\title{
As dimensões da auto-avaliação institucional: tecendo redes de redes
}

\author{
Lina Cardoso Nunes
}

\section{Resumo}

Este artigo tem o propósito de apresentar algumas reflexões sobre a rede de relações que se configuram nas dez dimensões abordadas pelo Sistema Nacional de Avaliação do Ensino Superior - SINAES, no âmbito do cenário contemporâneo. Cada uma dessas dimensões relaciona-se com as demais, estabelecendo redes entre pessoas, idéias, acontecimentos e práticas veiculadas no interior da universidade. São redes de redes. Constituem-se em uma trama complexa que exige da comunidade o conhecimento da identidade da cultura universitária, com o compromisso de garantir eticamente a fidedignidade dos relatos dos atores sociais participantes da avaliação. Ten-

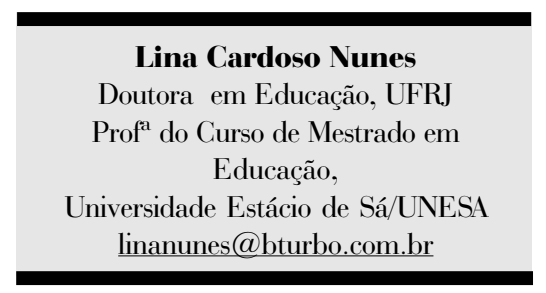
do em vista a avaliação de uma instituição de grande porte, avolumam-se as dificuldades para a realização coerente e consistente do processo avaliativo, em todas as dimensões, considerando-se os aspectos administrativos e acadêmicos envolvidos na análise dos processos avaliativos. Essa é tarefa a ser desempenhada pelos grupos institucionais administrativos e acadêmicos, apoiados pela Comissão Própria de Avaliação (CPA) e pela Coordenação Operacional Pedagógica (COP).

Palavras-chave: Redes de relações. Autoavaliação institucional. Universidade.

\section{Abstract \\ The dimensions of institutional self- evaluation: building networks of networks}

The aim of this article is to present some reflections on the relationship network that is established under the ten dimensions approached by the Sistema Nacional de Avaliação do Ensino Superior SINAES (Brazilian National System to Assess Superior Education) at the contemporary scene. All of the ten dimensions are interrelated in the university resulting in personal, ideas, facts, and practices networks. They are networks of networks. These nets are made up of a complex mesh that requires from the community the knowledge of the identity of the university culture, with the commitment of ethically garanteeing the accuracy of reports from all social players envolved with the assessment. Considering the evaluation of a large structure institution, there is an enlargement of difficulties for accomplishing, in all 
dimensions, a coherent and a consistent assessment process, taking in account administrative and academic aspects in the evaluation process analysis. This is the task to be accomplished by administrative and academic institutional groups enforced by the internal committee for assessment (CPA) and by operational coordination for pedagogical issues (COP).

Keywords: Relationship network. Evaluation process. University.

\section{Resumen}

\section{Las dimensiones de la auto evaluación Institucional tejiendo redes de redes}

En este artículo se presentan reflexiones acerca de la red de las diez dimensiones propuestas por el Sistema Nacional de Evaluación de la Educación Superior (SINAES). Cada una de estas dimensiones se interrelaciona con las otras, estableciendo vínculos entre las personas, las ideas, los eventos y las prácticas dinamizadas en el contexto de la universidad. Ellas son redes de redes, que se constituyen en una trama compleja que exige el conocimiento de la identidad y de la cultura de la universidad, con el compromiso de garantizar la credibilidad de los actores sociales participantes de la evaluación. Bajo el punto de vista la evaluación de una institución de gran porte, las dificultades se abultan para el logro coherente y consistente del proceso evaluativo, en todas las dimensiones, en especial los aspectos administrativos y académicos involucrados en el análisis del proceso evaluativo. Esta es la tarea a ser llevada a cabo por los grupos institucionales administrativos y académicos, incluso la propia Comisión Propia de Evaluación (CPA) y la Coordinación Operacional Pedagógica (COP).

Palabras claves: Red de relaciones. Auto-evaluación institucional. Universidad.

\section{Introduzindo o tema}

A idéia de rede está presente nos dias de hoje com os mais diversos significados - fala-se em rede ao citar os canais de televisão, o sistema bancário, os supermercados, entre outras formas de referência à idéia de rede, como as citadas por Gómez (2004, p. 27): "rede de espionagem, rede de emergência, rede de corrupção, rede de saúde pública, rede pública de educação, rede de computadores". A autora alude ainda à palavra-chave da sociedade interconectada - a globalização - "que possui em seu bojo a idéia de rede mundial aberta a múltiplas conexões".

Sob a ótica de Dias (2000, p. 150), "as qualidades de instantaneidade e simultaneidade das quais são dotadas as redes de telecomunicações deram livre curso a todo um jogo de interações ". Nesse âmbito, as tecnologias da informação e comunicação TIC, têm favorecido a emergência das relações entre pessoas, idéias e acontecimentos e práticas. São fluxos de informações que transitam celeremente pelos espaços e territórios, veiculando novas formas de pensar entre atores sociais e institucionais.

Assmann (2005, p. 14) refere-se à "era das redes", relacionada à expansão incrível das tecnologias digitais na sociedade da informação, referindo-se também à expansão das tecnologias da informa- 
ção e comunicação. No entanto, o que é sociedade da informação? Assmann (2005, p. 16) a define como:

[...] sociedade que está atualmente a constituir-se, na qual são amplamente utilizadas tecnologias de armazenamento e transmissão de dados e informação de baixo custo. Esta generalização da utilização da informação e dos dados é acompanhada por inovações organizacionais comerciais, sociais e jurídicas que alterarão profundamente 0 modo de vida, tanto no mundo do trabalho, quanto no mundo em geral.

Assim, conectam-se as idéias de rede, globalização e sociedade da informação, constituindo conceitos usados no cenário educacional, no interior das escolas, especialmente nas instituições de ensino superior. Nessa perspectiva, emerge o processo de avaliação institucional, proposto pelos órgãos oficiais - MEC / INEP, denominado Sistema de Avaliação do Ensino Superior - SINAES. Com a definição deste órgão oficial e suas diretrizes foi formulado o Plano de Auto-Avaliação da Universidade, utilizando a metodologia do empowerment ${ }^{1}$, que envolveu gestores, professores e funcionários na elaboração de metas, objetivos e estratégias para atingir os propósitos institucionais. São novas exigências para as instituições de ensino superior, que serão avaliadas no contexto de indicadores, calculados com o apoio de recursos tecnológicos capazes de detectar os possíveis enganos e/ou incoerências das informações disponibilizadas em relatórios finais de avaliação. Nesse contexto, torna-se indispensável estabelecer um sistema de informações consistente, a fim de que os dados coletados possam refletir concretamen- te o processo que se tiver desenvolvido na instituição, a partir da colaboração dos atores institucionais e seus órgãos colegiados, entre os quais se encontram os diretores administrativos dos órgãos superiores, os diretores de curso e os coordenadores acadêmicos.

Sob tal ótica, o presente artigo tem o propósito de elaborar uma breve análise da rede de relações que se configuram nas dimensões enfocadas pelo SINAES, entre pessoas, idéias e práticas.

\section{A auto-avaliação institucional: rede complexa de relações}

No decorrer do processo avaliativo, temse evidenciado a trama complexa constituída entre as pessoas da instituição com suas idéias, envolvidas com os acontecimentos do cotidiano em que estão inseridas e mergulhadas nas práticas exigidas pelas suas atribuições. Cada pessoa, de forma única, está ligada às demais pessoas da instituição, não só aquela que é responsável pela organização como um todo, como as que estão comprometidas e à frente dos diversos setores, incluindo-se os que estão submetidos à hierarquia, isto é, os funcionários que tanto podem ser ascensoristas, faxineiros, secretários, contadores, como os profissionais administrativos qualificados e/ ou os diretores, coordenadores e professores, mestres e doutores, que trabalham na área acadêmica/administrativa da universidade. Cada uma dessas pessoas tem um significado especial na rede de complexas relações que se estabelecem, de acordo com o perfil e a identidade da instituição.

\footnotetext{
1 A metodologia do empowerment permite que os atores do processo de avaliação sejam envolvidos no percurso das atividades, assim como sejam revisadas e/ou incorporadas novas metas, atendendo à dinâmica e ao espírito empreendedor da Instituição, orientando para questionamento constante e transformações decorrentes.
} 
conjunto dessas pessoas constitui o corpo social da instituição, como é o caso da universidade em foco - uma empresa particular, mas de caráter público, que abriga uma diversidade de pessoas - alunos, funcionários, professores, diretores, vice-reitor e reitor, das mais diversas camadas sociais, desde os menos favorecidos financeiramente, até os de classe social privilegiada no aspecto econômico - financeiro. Assim, estão reunidos na instituição pessoas, com costumes contraditórios, de culturas diferenciadas, vivendo em ambientes distintos. Avolumamse, nesse sentido, idéias, acontecimentos e práticas advindas dessa multiplicidade de pessoas que vêm contribuindo para o crescimento da universidade.

É nesse âmbito que se tem realizado a auto-avaliação institucional. A Comissão Própria de Avaliação - CPA, nomeada por ato do Reitor (Port. $n^{\circ} .105$ GR/2004), tem buscado atuar com o corpo social da universidade, principalmente nos seguintes aspectos: (a) orientação do processo avaliativo, tentando um "trabalho participativo", no contexto do empowerment e (b) fornecimento de "subsídios para o ajuste de ações acadêmico-administrativas" , na perspectiva de organizar e acompanhar a prestação de informações solicitadas pelo INEP" . (BRASIL, 2005).

documento oficial da Comissão Nacional de Avaliação do Ensino Superior CONAES, apresenta as dez dimensões da auto-avaliação, estabelecidas pela Lei do SINAES, assim denominadas: (1) A missão e o Plano de Desenvolvimento Institucional; (2) Perspectiva pedagógica e formadora de políticas, normas e estímulos para o ensino, a pesquisa, a pós-graduação e a extensão; (3) Responsabilidade Social das
IES, (4) Comunicação com a Sociedade; (5) Políticas de Pessoal, Carreira, Aperfeiçoamento e Condições de trabalho; (6) Organização e Gestão da Universidade; (7) Infra-estrutura Física; (8) Planejamento e Avaliação; (9) Políticas de atendimento a estudantes e egressos; e (10) Sustentabilidade Financeira. É, no contexto dessas dimensões, especialmente no que tange à rede administrativo-acadêmica, que se evidenciam as relações referidas neste artigo.

Tendo em vista as dificuldades emergentes para a avaliação de instituições de natureza complexa, relativa especialmente às suas características multicampi, como é o caso da instituição da qual fala o presente artigo, a atuação da CPA tem sido apoiada pela Comissão Operacional Pedagógica - COP, além de se terem dividido as responsabilidades do processo de avaliação institucional, com todos os diretores administrativos e pedagógicos dos 39 campi, que constituíram equipes colegiadas para auxiliar no desenvolvimento do processo. As tarefas são inúmeras, visto que devem ser consideradas tanto as atividades de natureza administrativa, quanto as de natureza acadêmica. Isto significa que em cada campi há redes das quais falamos que se articulam com as outras redes dos outros campi. São redes de redes...

Há, no entanto, um aspecto comum que perpassa todas essas redes. É a missão da instituição, transcrita a seguir, que tem orientado as ações da CPA e COP, assim como as ações de todos os campi e setores da universidade (UNIVERSIDADE ESTÁCIO DE SÁ, 2005):

[...] através da formação de recursos humanos qualificados, contribuir para o desenvolvimento científico, tecnológico e social do país com comprometimento ético e responsabilidade social, 
proporcionando o acesso de diferentes segmentos da população ao ensino de qualidade, articulado aos benefícios da pesquisa, da extensão e da formação continuada, privilegiando a descentralização geográfica e o valor acessível das mensalidades, buscando ao mesmo tempo a inclusão social na construção, pelo conhecimento, de uma sociedade mais justa, mais humana e mais igual.

A missão e o Plano de Desenvolvimento Institucional - PDI, constituem o eixo norteador do Projeto de Auto-avaliação Institucional. Uma das metas dessa dimensão tem sido a revisão deste plano, elaborado antes da constituição da CPA e aprovado no Conselho de Ensino e Pesquisa - CONSEPE, e Conselho Universitário - CONSUNI, para vigência no período de 2002-2006. Esta primeira dimensão "agrega ações e práticas que, desenvolvidas e consolidadas, refletirão a IES na sua essência" (UNIVERSIDADE ESTÁCIO DE SÁ, 2005). Decorrente da missão e do Projeto Pedagógico Institucional - PPI, já aprovado pelo CONSEPE e pelo CONSUNI, também em fase de revisão, é que pode ser concebido o Plano de Desenvolvimento Institucional - PDI. Em relação ao PDI, Segenreich (2005, p. 151) chama a atenção que

[...] uma análise da trajetória de construção de cada PDI se revela imprescindível no processo de avaliação institucional que as instituições de ensino superior estão iniciando no contexto do SINAES, principalmente tendo em vista que nem sempre se verifica ter sido o PDI fruto da referida construção.Em vez de se tornar um fio condutor do processo de avaliação, ele pode vir a se constituir um fardo incômodo para essas instituições se não for, também, objeto de avaliação.
Nesse sentido é que se torna indispensável a avaliação desse instrumento que se estrutura, tendo em vista: (a) Perfil Institucional; (b) Planejamento e Gestão Institucional e (c) Avaliação e Acompanhamento do Desempenho Institucional.Em princípio, a instituição em tela tem encontrado formas de crescer em quantidade, sem minimizar a preocupação com a qualidade, tanto nos setores administrativos quanto nos acadêmicos. No entanto, são observadas dificuldades para atender a todas as exigências legais, tendo em vista a ampliação progressiva do número de professores, alunos e setores espalhados pelos diversos campi da instituição, que exigem atenção cuidadosa a questões de planejamento, avaliação e desempenho dos diferentes grupos institucionais, tendo em vista a necessidade da atualização contínua da rede de informações organizada pelos órgãos administrativos e acadêmicos.

A segunda dimensão é a que trata da política para as áreas de Ensino, Pesquisa, Pós-Graduação lato sensu e stricto sensu e Extensão. É a que reúne todos os cursos da universidade, ou seja, graduação, graduação tecnológica, se for o caso, Pós-Graduação lato e stricto sensu, além da área de pesquisa e de extensão. Aqui se pode ressaltar a articulação dos componentes dessa dimensão: ensino, pesquisa e extensão, indissociáveis, visto que todos os cursos de Graduação apresentam seus eixos temáticos, que se integram, em suas especificidades aos cursos de Mestrado existentes nas diferentes áreas do conhecimento. Relevantes também são os cursos de Pós-Graduação lato sensu que, para muitos alunos já graduados, constituem a continuidade de sua formação profissional. Todos esses cursos tiveram oportunidade de reunir-se e elaborar 
o seu plano de auto-avaliação, tendo em vista suas características acadêmicas e/ou profissionais. Nessa dimensão, a Extensão Universitária tem aberto espaços para inúmeras iniciativas junto às comunidades, em que cada campus se insere, decorrentes de pesquisas e/ou atividades de ensino, que favorecem as ações vinculadas aos grupos inseridos no entorno da comunidade universitária, ampliando a rede de relações, entre outras dimensões, tais como a Responsabilidade social e a Comunicação com a Sociedade. Vale registrar que a segunda dimensão é a que tem mobilizado o maior número de funcionários da instituição, visto a quantidade de cursos de Graduação existentes no momento atual.

Fica evidente o caráter matricial que foi adotado para que se reunisse no relatório parcial (já enviado ao INEP/MEC) e no relatório final (em fase final de elaboração) todas as informações relativas aos cursos em funcionamento, no contexto dos diferentes campi da instituição.

A terceira dimensão voltada para a responsabilidade social é representada por grupos da instituição que trabalham em modalidades de ações relacionadas à contribuição para a inclusão social, ao desenvolvimento econômico e social, à defesa do meio ambiente, à memória cultural, à produção artística e ao patrimônio cultural (BRASIL, 2005).

Em fase anterior à implementação do Plano de Avaliação Institucional (2005) desenvolviam-se inúmeras iniciativas de responsabilidade social, algumas sem um planejamento que pudesse garantir a qualidade da atuação dos grupos responsáveis. Foi providenciada, no entanto, a ori- entação aos coordenadores dos projetos, para que se organizassem a fim de integrar-se à missão da universidade, no contexto do PPI. Assim, os referidos coordenadores, apoiados pela COP, têm envidado esforços para que se organizem as atividades realizadas em todos os campi e cursos, que buscam promover ações sociais, artísticas, culturais, educacionais, além de outras com objetivos orientados para a educação ambiental, para a inclusão social e para a orientação de cuidados com a saúde, muitas relacionadas a um esforço de integração com os objetivos dos projetos pedagógicos dos cursos.

No percurso do processo avaliativo da universidade, têm sido encontrados muitos entraves para que se elaborem e analisem os relatórios referentes às ações sociais implementadas na terceira dimensão, no contexto das especificidades socioculturais em que estão inseridas, tendo em vista a coerência e consistência das informações indispensável à produção desses relatórios, antes realizados, em alguns casos, de forma desarticulada das metas institucionais.

Uma dimensão que colabora para fortalecer as conexões entre todas as dimensões, possibilitando a construção da rede de relações dos projetos de auto-avaliação institucional é a quarta dimensão - a comunicação com a sociedade, isto porque "garante informações precisas, imediatas e em linguagem accessível à comunidade acadêmica e ao público em geral" (UNIVERSIDADE ESTÁCIO DE SÁ, 2005, p. 26). Essa dimensão tem merecido uma atenção especial dos responsáveis, considerando os desafios que enfrentam para estabelecer um sistema de comunicação eficiente e eficaz em uma instituição multicampi e de grande 
porte. É oportuno registrar a contribuição das tecnologias digitais para o processo comunicacional, tendo em vista os recursos inovadores possibilitados pela Internet, especialmente, por meio das comunicações via correio eletrônico, favorecedoras do envio de informações de maneira dinâmica e ágil. Nesse sentido, vários recursos foram implementados, buscando o contínuo aprimoramento dos aspectos relativos aos processos comunicacionais.

A quinta dimensão, significativa para levar a bom termo o trabalho docente e o das equipes técnico-administrativas da universidade, é a que se refere às políticas de pessoal, de carreira do corpo docente e do corpo técnico e administrativo. É uma dimensão estreitamente vinculada à organização, à gestão da universidade e à sustentabilidade financeira. Apresenta-se, nesse âmbito, uma rede de relações estabelecidas entre os que estão à frente da instituição e são responsáveis pelos aspectos gerenciais, administrativos e financeiros, respectivamente abordados nas dimensões 6 - organização e gestão da instituição e 8 - sustentabilidade financeira. Em princípio, para a CPA e a COP, cuja esfera de ação, em uma universidade privada, é especialmente, na instância acadêmica, essa dimensão configura uma série de dificuldades para ações transformadoras e participativas, se comparada com as possibilidades de ação nas dimensões voltadas para a área acadêmica, como, por exemplo, a dimensão 2 - relativa à Perspectiva pedagógica e formadora: políticas, normas e estímulos para o ensino, pesquisa e extensão. No entanto, a CPA e a COP têm empreendido uma atuação política efetiva junto aos gestores, que têm sido receptivos na análise das questões relacionadas a essas dimensões, com vistas ao seu progressivo aprimoramento.
Na dimensão 6 - organização e gestão da instituição - situam-se os órgãos colegiados e os campi, "que obedecem ao perfil multicampi da instituição, trabalhando numa estrutura matricial, e sustenta e legitima a autonomia de seus campi [...] respeitados os princípios de unicidade e organicidade" (UNIVERSIDADE ESTÁCIO DE SÁ, 2005, p. 29). No contato com os diretores das diversas unidades da instituição, a CPA e a COP têm buscado atuar colaborativamente, ensejando a análise e a discussão de aspectos críticos que podem ser revistos e aprimorados. Nesse sentido, foram criados colegiados em todos os setores acadêmicos e administrativos da instituição, a saber: cursos de Graduação, Graduação Tecnológica, cursos de Pós-Graduação lato sensu e strito sensu e órgãos gestores da universidade.

A sétima dimensão - A infra-estrutura física - está integrada a todas as dimensões, mas, destacamos, especialmente seu significado para a subdimensão ensino, vinculada à segunda dimensão, que não prescinde de salas com razoável conforto, boas instalações elétricas, atualização constante de livros e periódicos, laboratórios bem equipados, entre outros, os de Informática. Aqui enfatizamos que compreendendo a importância dessa dimensão, especialmente em relação a aspectos como a biblioteca e os laboratórios, que sustentam o funcionamento da IES, atendendo às necessidades dos alunos, a instituição estabeleceu metas e prioridades em todos esses aspectos e tem alcançado índices favoráveis para a qualidade de seus serviços, tanto na área acadêmica, quanto nos setores administrativos, de acordo com as avaliações externas do MEC / INEP. 
A oitava dimensão, relativa ao Planejamento e Avaliação, está ligada a todos os setores institucionais, pois todos são periodicamente avaliados e, dependendo dos resultados, podem ser replanejados. É um dos aspectos fundamentais da rede de relações, juntamente com a primeira dimensão - A missão e o Plano de Desenvolvimento Institucional. De acordo com Segenreich (2005, p. 151), o PDI "deve tornar-se referência básica para o estabelecimento de qualquer critério ou processo de avaliação". Assim, a dimensão "Planejamento e Avaliação" articula-se com o referido plano, acompanhando o processo em todas as outras dimensões e nos setores administrativos que as organizam e são por elas responsáveis, numa perspectiva de meta-avaliação, isto é, avaliando as avaliações em cada uma das etapas traçadas no Projeto de Auto-avaliação Institucional.

Como todas as dimensões, esta não prescinde dos recursos tecnológicos característicos da era das redes, conforme enuncia Assmann (2005), a fim de que possa transmitir e receber informações, possibilitando o acesso aos diretores de campi e de curso, além dos gestores da parte técnicoadministrativa. As pessoas, reunidas em seus setores, com seus planos e idéias, enredados nos acontecimentos e nas práticas institucionais, nesse caso especial, nas práticas avaliativas, procuram integrar-se à rede de relações e à divulgação das informações que este plano de auto-avaliação tem propiciado.

A nona dimensão diz respeito às políticas de atendimento aos estudantes e egressos, ou seja, todos aqueles que passam e passaram pelos diversos espaços da universidade, em que são construídos saberes, em que se formam pessoas, para as mais diversas instâncias profissionais, com suas idéi- as, seus planos futuros, envolvidos nos acontecimentos e nas práticas institucionais vivenciadas em seus percursos na IES. Esses são os principais atores desse cenário, para os quais se dirigem as preocupações da instituição. Assim, todas as dimensões, sem exceção, têm também seu foco nesta dimensão, para que sejam atendidos seus interesses e necessidades emergentes.

Vale sinalizar, no entanto, que nada seria possível sem a décima dimensão - a sustentabilidade financeira, - que "garante a segurança das operações financeiras, visando ao cumprimento da missão da instituição" (UNIVERSIDADE ESTÁCIO DE SÁ, 2005, p.44). A gestão, nesse aspecto, assume relevância especial, em se tratando de uma universidade particular, que gera recursos e os administra, além de planejar a captação e alocação de recursos, tendo em vista os princípios anunciados em sua missão. Assim, tem o compromisso de promover " políticas direcionadas à aplicação de recursos para programas de ensino, pesquisa e extensão" (BRASIL, 2004, p. 36).

Constrói-se a rede das redes, em torno de pessoas que administram, planejam, dirigem, implementam, coordenam, otimizam, ensinam, orientam, aprendem, avaliam, todos estreitamente vinculados a suas idéias e ações, envolvidos nos acontecimentos e nas práticas, vivendo desafios, conflitos, dissensos, confrontos, contradições, mas também buscando a harmonia, o consenso, a interação e a cooperação. Nesse contexto, se configura a identidade institucional da universidade. De acordo com Silva Junior e Sguissard (2005, p. 20): "A avaliação é um momento ético da prática universitária, no qual os atores institucionais deviam pontuar se estão consolidando no que fazem uma cultura que realiza a identidade da cultura universitária". 


\section{Concluindo provisoriamente}

A era das redes (ASSMANN, 2005) está ao nosso alcance. Apresenta-se de muitas formas: tanto nas relações que se estabelecem entre os atores sociais da IES, quanto nos inúmeros recursos de informação e comunicação hoje acessíveis aos mais diversos setores da universidade. Os fluxos de informações (DIAS, 2000) estão presentes nos meios de comunicação de massa - na televisão, na mídia impressa e online invadindo os espaços onde vivemos. É tempo da globalização, que possui em seu bojo a idéia de múltiplas conexões (GOMEZ, 2004).

Nesse cenário, surgiram as Diretrizes para a Avaliação do Ensino Superior, que constituem exigências de preenchimento de documentos com informações precisas sobre todas as atividades desenvolvidas nas universidades. São dezenas de tabelas de dados que retratam as instituições com suas características, pormenorizadamente, capazes de demonstrar como as universidades têm levado a cabo a sua missão ou não. Esse conjunto de tabelas formam redes de informações de critérios e indicadores explícitos para cada uma das dimensões e atribuição de conceitos, em ordem decrescente, variando de 5 (cinco) a 1 (hum), mostrando em que medida a instituição alcançou as exigências definidas pela grande rede: a das Políticas de Ensino Superior.

Assim, a complexa teia de relações constituída em cada instituição de ensino superior, em que cada setor se subordina às determinações dos que a chefiam, está subordinada à grande rede, que reúne todas as universidades brasileiras.

Cabe aqui alertar para a afirmação de Macedo e outros (2005, p. 134): "não podem ser repetidos os equívocos do passado recente que dificultam a construção de uma avaliação que leve em conta a diversidade regional, as peculiaridades, as características e a missão das Instituições de Ensino Superior".

Impõe-se que as instituições de nível superior reflitam sobre seu papel na sociedade atual, considerando sua identidade e o contexto regional no qual se inserem; analisem os resultados obtidos na totalidade dos dados coletados, tendo em vista não somente a dimensão quantitativa, mas buscando a dimensão qualitativa do processo, com o propósito de desvelar as fragilidades e potencialidades emergentes da avaliação e tentando visualizar como superar os entraves mais sérios decorrentes dos resultados da análise. As instituições que abrirem espaços para a discussão com os atores do processo, provavelmente, poderão obter resultados favoráveis. Nessa perspectiva, foram viabilizados os Seminários de Auto-avaliação Institucional, assim como as reuniões periódicas entre os órgãos administrativos e acadêmicos da instituição em foco.

No caso da IES em foco, a CPA e a $\mathrm{COP}$, junto à comunidade universitária, têm buscado permanentemente estabelecer uma parceria, de forma dialógica com os que estão à frente da instituição, a fim de que possamos alcançar cooperativamente um patamar que demonstre a seriedade dos compromissos assumidos e coerentes com a missão anunciada pelos que estão à frente da universidade. 


\section{Referências}

ASSMANN, H. Redes digitais e metamorfose do aprender. Petrópolis, RJ: Vozes, 2005.

BRASIL. Ministério da Educação. Comissão Nacional de Avaliação do Ensino Superior (CONAES). Diretrizes para a avaliação de instituições do ensino superior. Brasília, DF, 2005. Disponível em: <http://portal.mec.gov.br>. Acesso em:

2 out. 2006.

Avaliação externa das Instituições de Ensino Superior: diretrizes e instrumentos. Brasília DF: CONAES, INEP, 2005. 48 p.

- Sistema Nacional de Avaliação de Ensino Superior. Orientações gerais para o

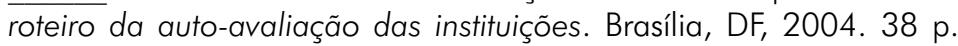

DIAS, L. C. Redes: emergência e organização. In: CASTRO, I. E.;

GOMES, P. C. C.; CORREA, R. L. Geografia: conceitos e temas. Rio de Janeiro: Bertrand Brasil, 2000. 352 p.

GOMEZ, M. Educação em rede: uma visão emancipadora. São Paulo: Cortez: Instituto Paulo Freire, 2004.

INSTITUTO NACIONAL DE ESTUDOS E PESQUISAS EDUCACIONAIS ANÍSIO TEIXEIRA. Manual do Exame Nacional do Desempenho Escolar: ENADE 2004. Brasília, DF, 2004.

SILVA JUNIOR, J. R.; SGUISSARD, V. A nova lei de educação superior: fortalecimento do setor público e regulação do privado mercantil ou continuidade da privatização e mercantilismo do publico. Revista Brasileira de Educação, Rio de Janeiro, n. 29, p. 527, maio/ago. 2005.

MACEDO, A. R. et al. Educação superior no século XXI e a reforma universitária brasileira. Ensaio: avaliação e políticas públicas em educação: revista da Fundação Cesgranrio, Rio de Janeiro, v.13, n. 47, p. 127-148, abr./jun. 2005.

SEGENREICH, E. C. O PDI como referente para a avaliação das Instituições de Ensino Superior: lições de uma experiência. Ensaio: avaliação e políticas públicas em educação: revista da Fundação Cesgranrio, Rio de Janeiro, v.13, n. 47, p. 149-168, abr./jun. 2005.

Recebido em: 10/07/2006

Aceito para publicação em: 21/08/2006 